\title{
Acute pigmented tubulopathy and interstitial nephritis following wasp sting
}

\author{
WTP Gunasekera ${ }^{1}$, Lakmini Mudduwa ${ }^{2}$, Sarath Lekamwasam ${ }^{3}$ \\ ${ }^{1}$ Registrar in Medicine, Teaching Hospital, Karapitiya, Galle. \\ ${ }^{2}$ Senior Lecturer in Pathology, ${ }^{3}$ Professor in Medicine, Faculty of Medicine, University of Ruhuna, \\ Karapitiya, Galle.
}

\section{Introduction}

Wasp stings are usually followed by minor local allergic reactions and rarely anaphylaxis ${ }^{1,2}$. Systemic complications such as acute renal failure, myocarditis, acute encephalopathy, Guillain-Barré syndrome, thrombocytopenia and vasculitis have been described following multiple wasp stings. Renal impairment is also reported and commonly results from acute tubular necrosis secondary to intravascular haemolysis, rhabdomyolysis or shock ${ }^{3-6}$. Acute renal failure secondary to tubular-interstitial nephritis has been descried in few instances ${ }^{7}$. We report an uncommon variety of acute interstitial nephritis associated with wasp sting.

\section{Case report}

A 45 year old man was bitten by about 50 wasps. He was stung on the face, chest and upper limbs and was admitted to a local hospital with pain, swelling and redness of affected areas. Due to the worsening of facial swelling he was transferred to Teaching Hospital, Karapitiya about 14 hours after the incident. He was treated with oral antihistamines and a short course of oral steroids. Next day he was sent home to be reviewed in two weeks. His blood urea and serum electrolytes were normal.

Two days after discharge, he developed reduced urine output, facial swelling, abdominal pain and vomiting. On examination his blood pressure was 180/90 $\mathrm{mmHg}$ and jugular venous pressure was elevated. He was initially oliguric but two days later became polyuric. His blood urea during the second admission varied from 69 to $119 \mathrm{mg} / \mathrm{dL}$. Serum Creatinine level was 6.6 $\mathrm{mg} / \mathrm{dl}$. Serum sodium and potassium were initially normal and both were reduced during the polyuric phase. Urine analysis showed 10-15 pus cells per field but there were no abnormal sediments. His blood pressure was controlled with oral amlodipine and frusemide.

The renal biopsy, performed during the second admission, showed interstitial mononuclear cell infiltration with focal tubular epithelial necrosis. A brown pigment was present in the tubular epithelium. The glomeruli were unremarkable. These findings were consistent with tubulointerstitial nephritis with pigmented tubulopathy.

\section{Discussion}

Stinging insects are classified as Hymenoptera which includes Vespids and Apids. Wasps fall into the Vespid category. Though wasp stings are usually followed by mild local reactions, complications such as angioedema, vasculitis, encephalitis ${ }^{8}$ intravascular haemolysis, rhabdomyolysis, thrombocytopenia ${ }^{9}$, acute tubular injury, acute myocardial infarction ${ }^{10}$ and acute hepatic injury ${ }^{11,12}$ have been reported. Venom comprises of a concentrated mixture of complicated active components such as apamine, phospholipase, melittin, hyaluronidase, acid phosphatase, histamine and kinin. These have haemolytic, neurotoxic and vasoactive properties which can cause intravascular haemolysis and rhabdomyolysis. Though renal impairment is usually due to acute tubular necrosis, acute tubulo-interstitial nephritis leading to acute renal failure has also been reported. Chao et al. in 2004 reported a case of acute interstitial nephritis with pigmented tubulopathy following wasp sting ${ }^{10}$ but no further reports of this particular complication could be found. Lack of data prevented us from determining the clinical significance of this condition or whether the appearance of tubular pigments is specific to particular species of 
insects. Furthermore, as it is not well documented, whether histopathologists routinely observe for the presence of pigments in tubular cells is questionable. It is important to observe for this histological feature to see the clinical relevance and how it differs from the commonly observed acute interstitial nephritis associated with wasp sting.

\section{References}

1. Habermann E, Bee and wasp venoms. Science 1972, 177: $314-22$.

2. Frankland AW, Lessof MH, Allergy to Bee sting: A review. Journal of Royal Society of Medicine 1980; 73: $807-10$.

3. Bousquet J, Huchard G, Michel FB. Toxic reactions induced by hymenoptera venom. Ann Allergy 1984; 52: $371-4$

4. Sakhuja V, Bhalla A, Pereira BJ, Kapoor MM, Bhusnurmath SR, Chugh KS, Acute renal failure following multiple Hornet stings. Nephron 1988; 49: 319-21.

5. Chug KS, Sharma BK, Singral PC, Acute renal failure following Hornet stings. Journal of Tropical Medicine and Hygiene 1976; 79: 42-4.
6. Humblet Y, Sonnet J. Bee stings and acute tubular necrosis. Nephron 1982; 31: 187-9.

7. Zhang R, Meleg-Smith S, Batuman V. Acute tubulointerstitial nephritis after Wasp stings. American Journal of Kidney Disease 2001; 38: e33.

8. Abuelo JG, Renal failure caused by chemicals, plants, animal venoms and misuse of drugs. An overview Archives of Internal Medicine 1990; 150: 505-10.

9. Bousquet J, Huchard G, Michel FB, Toxic reactions induced by hymenoptera sting. Venom Ann Allergy 1984; 52: 371-4.

10. Levine HD, Acute myocardial infarction following Wasp stings. American Heart Journal 1976; 91: 36574.

11. Jones W, Shingar M. Severe hepatic and renal damage following Wasp bites. Dapin Refuiim (Bha Medica) 1964; 22: 353-56.

12. Glaser M. A fatal case after Hornet stings and Benadril medication. Hasetuah 1956; 50(8): 175-6.

13. Chao YW, Yang AH, Ng YY, Yang WC. Acute interstitial nephritis and pigmented tubulopathy in a patient after wasp stings. Am J Kidney Dis 2004; 43(2): $15-9$. 